\title{
LA SEGURIDAD JURÍDICA: ENTRE LA TRADICIÓN Y LA RENOVACIÓN DEL DERECHO
}

\author{
DIANA PATRICIA QUINTERO MOSQUERA
}

Introducción.La suerte del derecho en Colombia no es preocupación exclusiva de juristas; los miembros de la sociedad se sienten autorizados a opinar sobre un fenómeno presente en casi todos los ámbitos de sus vidas. Por esto en la actualidad escuchamos voces críticas que culpan a la inseguridad jurídica en materia económica por la ausencia de inversión extranjera y la huida de capitales del país. Estos factores impactan negativamente las actividades productivas, al generar desempleo, decrecimiento económico, y consecuencias similares. El año pasado, a raíz del fallo de la Corte Constitucional que ordenó el reajuste salarial para los empleados públicos discriminados por la ley 547 de 1999, las críticas se centraron en el papel de los jueces constitucionales. Se les acusó de ser insensibles frente a los efectos económicos de sus decisiones, y de fomentar un ejercicio despótico del derecho. Esta intervención en la economía es percibida como una intromisión ilegítima de los jueces, y ha llevado a algunos a plantear como deseable la supresión de la Corte Constitucional.

Una de las opiniones más fuertes en contra de las decisiones con efectos prestacionales es sostenida por el economista Salomón Kalmanovitz. En su calidad de miembro de la Junta Directiva del Banco de la República ha manifestado: "La Corte Constitucional se ha erigido en un enorme poder (...) ha usurpado funciones del poder legislativo y del ejecutivo para ordenar que se haga legislación de acuerdo con sus conceptos (...) se ha tornado en una autoridad que define a qué sectores debe beneficiar el gasto público y en qué cuantías (...) las cortes pretenden defender los bancos públicos y están cambiando las reglas frecuentemente, agregando riesgos de regulación, de inseguridad jurídica permanente y de malos incentivos que vulneran aun más los derechos privados" ${ }^{1}$. El tono de estas afirmaciones evidencia un descontento con el sentido que la Corte Constitucional ha dado al derecho. Pero el elemento constante en todos los opositores del tribunal es la crítica al carácter permanente de la inseguridad jurídica en el contexto colombiano.

${ }^{1}$ Salomón,. Kalmanovitz, Las instituciones colombianas en el siglo XX , Ed. Alfaomega, Cambio, Bogotá D.C., enero de 2001. Págs 27 - 29. 
Parece un hecho notorio la pérdida de seguridad jurídica entendida en su forma clásica: la previsibilidad de las decisiones de los tribunales, que sirve a los destinatarios del derecho para orientar su comportamiento ${ }^{2}$. Cada cual busca a los culpables de esa pérdida entre el Gobierno, las altas Cortes, el Banco de la República, etc. Pero hay un aspecto ligado al concepto de derecho que se suele pasar por alto y cuya consideración puede contribuir a la comprensión del fenómeno que nos ocupa. La seguridad jurídica vigente antes de la expedición de la Constitución de 1991, suponía un acuerdo sobre la reducción del derecho a la ley positiva y el papel inferior del juez, como siervo de dicha ley. El orden institucional establecido durante la última década requiere de un nuevo acuerdo entre los ciudadanos, sobre el sentido y el alcance del derecho en la actualidad nacional. La seguridad jurídica posible hoy está condicionada por las modificaciones sufridas por el derecho en Colombia, a lo largo de la última década. Se trata de variaciones en el contenido, interpretación, método, modo de enseñanza, de estudio, y de aplicación del derecho.

A menudo, las personas vinculadas a las distintas organizaciones que componen la sociedad se sorprenden cuando se habla de los cambios que ha sufrido el modo de pensar el derecho, o de la existencia de nuevos paradigmas del saber jurídico en nuestro país. Sin embargo, encontramos en la realidad diversas nociones del derecho orientando el tipo de decisiones judiciales y gubernamentales que se adoptan. Este artículo pretende mostrar cómo lo que en ocasiones se percibe como ausencia de seguridad jurídica, no es sino el resultado de los cambios en la concepción y práctica del derecho. Como se lee en una sentencia de la Corte Constitucional, los acontecimientos de los últimos años: "han producido en el derecho no sólo una transformación cuantitativa debida al aumento de la creación jurídica, sino también un cambio cualitativo, debido al surgimiento de una nueva manera de interpretar el derecho" 3 .

La falta de un acuerdo alrededor de una única noción de derecho explica, aunque de manera parcial, la inseguridad jurídica aludida. Esta no se agota en la preocupación sobre las normas que serán aplicadas por jueces o gobernantes en la solución de los distintos conflictos que se presenten. Involucra una segunda cuestión sobre cuáles elementos adicionales a las normas servirán de fundamento a las decisiones; interrogante que alude a la intervención de lo político y lo ético en el derecho. Y una tercera cuestión, sobre cuáles cambios en la normatividad promoverán los gobiernos sucesivos, bajo la presión de diversos grupos de interés. Responder a este último interrogante requiere una reflexión sobre el entorno político en que se desenvuelve la actividad productiva; reflexión que no se llevará a cabo en el presente artículo. En cambio, se estudiará la segunda cuestión que se refiere al contenido del derecho en la actualidad.

La pregunta que abordaremos es la de si el derecho se agota en el conjunto de normas producidas por quienes ejercen el poder político, o si involucra elementos adicionales y cuáles serían esos elementos. De aceptar una noción más amplia de derecho, debemos interrogarnos sobre cuáles serían el método y el papel del jurista en ese nuevo marco conceptual.

\footnotetext{
${ }^{2}$ Véase, H. Kelsen, Teoría pura del Derecho, Porrúa, México D.F., 1995, pág 260.

${ }^{3}$ Sentencia T-406/92. Magistrado Ponente Ciro Angarita Barón.
} 
a. La polémica en el ordenamiento jurídico colombiano actual.

Aunque en algún momento de nuestra historia como República se impuso una determinada tradición jurídica, en la actualidad asistimos a un cambio significativo del pensamiento y prácticas tradicionales. El sentido del cambio no es lineal; por el contrario, las concepciones presentes se entrecruzan o se superponen por períodos. El conocimiento de la concepción tradicional nos permite medir el alcance y significado de las transformaciones. Nos da luces además, para entender el conflicto actual entre las perspectivas tradicional y de renovación del derecho.

Esa tensión entre lo "viejo" y lo "nuevo", que podemos denominar "formalismo vs. anti-formalismo", expresa la oposición entre dos concepciones jurídicas. Una concepción normativa percibe el derecho como el conjunto de normas producidas y consagradas positivamente a efectos de garantizar la seguridad jurídica. Una concepción realista lo define como el conjunto de decisiones que permiten alcanzar la equidad o justicia en un caso particular ${ }^{4}$. Algunos académicos describen la polémica como el resultado de la interpretación realizada por la Corte Constitucional durante la última década ${ }^{5}$. Para estos, antes de la Constitución de 1991 la perspectiva dominante era formalista; mientras que, a partir del trabajo de adjudicación de la Corte, se va consolidando un desplazamiento hacia el realismo jurídico.

¿Posee alguna de esas corrientes que se expresan en el contexto colombiano actual, el concepto "verdadero" del derecho?. La respuesta es negativa, si tomamos en serio la afirmación del jurista Carlos Santiago Nino, para quien no existen unas nociones verdaderas y otras falsas del concepto. Simplemente, hay unas con mayor justificación o justificadas de manera más racional que otras ${ }^{6}$.

A fin de identificar las razones que han servido de justificación a la concepción formalista en Colombia, es necesario remitirse a algunos sucesos históricos acaecidos en los orígenes de la República. No pretendemos hacer un estudio histórico riguroso, exhaustivo. Simplemente queremos mencionar rápidamente dos fuentes de nuestra tradición y delinear los rasgos de una de ellas: el benthamismo jurídico, para señalar cuáles de esos rasgos se mantuvieron y cuáles no.

b. Las fuentes de nuestra tradición jurídica.

La teoría jurídica tradicional como ha sido transmitida en las escuelas, reduce el derecho a las normas de carácter coactivo, general y abstracto, creadas por el Estado o poder político. Esas normas se denominan "ley", y su cumplimiento es asegurado por la fuerza física ejercida por el poder político sobre los ciudadanos. El carácter general, impersonal y abstracto de la ley así concebida garantiza el principio de igualdad

\footnotetext{
${ }^{4}$ Sobre este debate Véase C. Borrero, “La Justicia comunitaria: ¿Peón de sacrificio o torre de marfil?”, en: Pensamiento jurídico, Facultad de derecho, ciencias políticas y sociales de la Universidad Nacional de Colombia, No. 12 Bogotá, 2000, págs 14 y 15. Y E. Ardila Amaya, "Justicia comunitaria: claves para su comprensión”, ibid, pág 45.

${ }^{5}$ C. Rodriguez, "El test de razonabilidad y el derecho a la igualdad", en La corte constitucional, el año de la consolidación, Siglo del Hombre editores, Bogotá, 1998. Págs 261 a 267.

${ }^{6}$ C.S.Nino, Derecho, moral y política, Ariel, Barcelona, 1994, p. 41
} 
jurídica: los ciudadanos quedan todos cobijados de igual manera por las disposiciones legales. La concepción normativa a partir de la cual el derecho se agota en la ley positiva, fue incorporada a nuestra tradición en el siglo XIX. Los juristas de entonces buscaban desplazar el derecho casuístico propio de la época de la Colonia. Tal propósito se debió en parte al contacto que las elites criollas más progresistas sostuvieron con juristas europeos, provenientes de distintas ideologías.

Uno de los frutos del contacto con Europa fue el "liberalismo utópico" dado en la Nueva Granada entre 1850 y 1870; período que ha sido bien caracterizado por Alfredo Vázquez Carrizosa. Para él, durante esos años se intentó convertir el Estado en una confederación compuesta por entidades territoriales soberanas. Los rasgos básicos de dicho intento se expresan en la descripción del Estado como un aparato "con libertades absolutas de imprenta y enseñanza, libre comercio extranjero y la abolición del ejército permanente, por estimarlo opuesto al concepto de las libertades absolutas". Se trata de un momento de la vida institucional de la Nueva Granada, durante el cual se implanta una utopía libertaria, en detrimento de la autoridad presidencial ${ }^{7}$. El derecho, creación de dicho Estado, es percibido como un freno a las libertades individuales. La proliferación de normas es una cortapisa para el desarrollo y despliegue de los ciudadanos, en tanto restringe la iniciativa privada. A pesar de ese prejuicio hacia el derecho, este liberalismo logró orientar parte importante de la legislación neogranadina del momento. A ello contribuyó el triunfo liberal del general José Hilario López; quien fue elegido por el Congreso en marzo de 1849. Entre las normas promulgadas bajo el influjo de este liberalismo "radical" encontramos la ley del 12 de junio de 1849, mediante la cual se abolió el monopolio del tabaco y se crearon posibilidades para la comercialización de la agricultura. De igual modo, la ley del 26 de mayo del mismo año, que suprimió la pena de muerte para los delitos de naturaleza política. Y la ley del 21 de mayo de 1851 declaró la libertad para todos los esclavos del territorio nacional.

Una segunda fuente de nuestra tradición fue el benthamismo jurídico, en algunos de sus aspectos. Algunos años después de proclamada la independencia de la República, el pensamiento de Jeremías Bentham se incorporó a la enseñanza universitaria de los asuntos jurídicos y políticos. Con esta medida se intentaba desplazar la lógica jurídica propia de la Universidad colonial. Es famosa la amistad existente entre Bentham y Francisco de Paula Santander ${ }^{8}$. Este último instituyó, mediante decreto, el Tratado de Legislación del jurista inglés, como obra de estudio obligatorio en las Facultades de Jurisprudencia y en la enseñanza media de Ética. Durante este período, los neogranadinos buscaban racionalizar el Estado a través de la legislación y la tecnificación 9 . Para lograrlo, adoptaron la idea de Bentham de crear un sistema de normas jurídicas claras, fundadas en un principio racional: el de la mayor felicidad

\footnotetext{
${ }^{7}$ Véase A. Vázquez Carrizosa, "La disolución de la gran Colombia", en El poder presidencial en Colombia, Enrique Dobry editor, Bogotá, 1979, págs. 94 - 98.

${ }^{8}$ El itinerario de esta amistad consta en la correspondencia y en los escritos de Santander que conforman sus diarios de viaje. Véase, Santander en Europa. Diario de viaje 1829-1830, Presidencia de la República de Colombia - Banco de la República, Bogotá 1989, págs 7, 10, 11, 183, 184, 187, 206, 208 y 209. Santander en Europa Diario de viaje 1830 - 1832, pág. 118. Santander en Europa Cartas de viaje, 1829 - 1832, págs 42, 43, 44, 73, 83 y 98.
} 
para el mayor número de personas; principio que sirve de criterio para la moralidad tanto particular como institucional.

La importancia y posterior permanencia del benthamismo se debió, en parte, al deseo de los fundadores de la República de realizar una organización racional y eficaz del Estado. La formulación jurídica de Bentham, según ellos, adoptaba como principio fundante la generalidad de la ley y ofrecía una concepción del derecho desligada de cuestiones religiosas o morales. La pretensión de algunos sectores de las elites criollas era instaurar un sistema jurídico que obligara a todos por igual, y se pudiera diferenciar de las valoraciones de quienes ejercían el poder. El respeto del principio democrático de generalidad de la ley, adoptado por los benthamistas, garantizaba la seguridad jurídica y en ese sentido inauguraba un ordenamiento respetuoso de uno de los principales derechos de los ciudadanos. El Estado de derecho no sería ya, como en el liberalismo vinculado a la tradición iusnaturalista ${ }^{10}$, un Estado capaz de garantizar la obediencia a normas universales e inmutables, de contenido vago e indeterminado. En adelante regirían las normas escogidas por el soberano, aunque su contenido no coincidiese con el derecho natural. Bentham vió en el iusnaturalismo al mayor enemigo de la seguridad jurídica y logró transmitir esta prevención a sus seguidores neogranadinos ${ }^{11}$. La tradición jurídica instaurada por este camino se concretó en una concepción normativa, formalista; para la cual la coacción y la voluntad del poder político ocupaban un lugar central, como elementos que distinguen a la Jurisprudencia, es decir la ciencia del Derecho, de otras expresiones normativas como la moral ${ }^{12}$.

De todos los elementos incorporados así por nuestra tradición, hay sin embargo, uno que no puede ser atribuido en propiedad a Bentham: el formalismo estricto. Algunos aspectos básicos del pensamiento del jurista inglés fueron olvidados en algún momento por nuestra historia institucional. En primer lugar, su convicción sobre la necesidad de contar en la sociedad con censores, o teóricos dedicados a resaltar los aspectos "irracionales" o "inconvenientes" de la legislación ${ }^{13}$. En segundo lugar, la afirmación

\footnotetext{
${ }^{9}$ Sobre este período de nuestra historia es ilustrativo consultar a Jaime Jaramillo Uribe en su texto El pensamiento colombiano en el siglo XIX, Temis, Bogotá, 1982, págs 135 - 155.

${ }^{10} \mathrm{~A}$ pesar de la existencia de múltiples nociones de iusnaturalismo, podemos definirlo como aquella corriente para la cual sólo constituyen derecho aquellas normas cuyo contenido es acorde con las leyes eternas, inmutables y de validez universal que los hombres pueden extraer de la voluntad de Dios o bien pueden extraer del conocimiento de la naturaleza humana.

${ }^{11}$ Véase, J. Bentham, Fragmento sobre el gobierno, Aguilar, Madrid 1973, Págs 42 - 46.

12 "El fin de la ética privada es la felicidad, igual que el de la legislación; se trata de la felicidad de cada miembro de la comunidad. Las personas cuya felicidad debe buscarse son las mismas, jen donde radica entonces la diferencia? Hay una diferencia en los actos de que tratan ambas. El hombre debe realizar aquellos actos que le producen felicidad y producen felicidad a los demás, pero el legislador no siempre debe, vía coacción, intentar dirigir la conducta de los miembros de la comunidad" J. Bentham, The principles of morals and legislation, Prometheus Books, New York, 1988, págs 313 y 314. (traducción mía).

${ }^{13} \mathrm{~J}$. Bentham distingue entre el expositor y el censor. El primero es el encargado de explicar lo que la ley es, es decir, aquello que el legislador y su subordinado - el juez- han hecho previamente. El segundo se encarga de fijar lo que la ley debe ser, y en ese sentido, lo que el legislador debe hacer en el futuro. El trabajo de este último es lo que permite a un sistema progresar. Ver Fragmento sobre el gobierno, pág. 11.
} 
de que los creadores tradicionales del derecho, denominados por la teoría jurídica "el legislador", no son tan racionales como supone una concepción normativa del derecho. Y en tercer lugar, para Bentham las decisiones de los tribunales también constituyen normas jurídicas, es decir derecho ${ }^{14}$. Además, el derecho debe fundarse en un principio moral: el principio utilitarista del bienestar general. Este hecho hace del pensamiento de Bentham una teoría jurídica sustantiva, comprometida con una idea de bien - la felicidad del mayor número.

Nuestra concepción tradicional redujo el derecho a la ley positiva y coactiva producida por el poder político, al excluir los principios generales y la costumbre. Desconoció el papel de las decisiones judiciales o precedentes como fuentes de derecho y dejó a los juristas la tarea de describir una legislación considerada fruto de un legislador racional incapaz de dejar vacíos o de incurrir en contradicciones ${ }^{15}$.

c. Sobre el método en la tradición jurídica colombiana.

Otro de los aspectos que se ha transformado en los últimos años, y cuya formulación tradicional permite entender el contenido del cambio es el método del derecho. Nuevamente fue Bentham, con el concurso posterior de su discípulo John Austin, quien inspiró los desarrollos metodológicos dados a lo largo de los primeros años de la República. El método se tornó descriptivo -descripción de las normas positivasseparado de cuestiones valorativas de naturaleza moral o política ${ }^{16}$. Durante el siglo XX se sumó el influjo del jurista Hans Kelsen, quien formuló una concepción formalista y positivista del derecho.

La adopción de los postulados kelsenianos fue un hecho importante. Nuestras escuelas tradicionales enfatizaron en la idea de ciencia jurídica: disciplina fundamental, referida a la actividad del jurista, de describir las normas que forman el ordenamiento jurídico. La filosofía del derecho, la sociología jurídica, la antropología del derecho, etc., se consideraron disciplinas auxiliares. Su tarea, se afirmó, es ocuparse del ordenamiento jurídico de manera externa, en tanto lo valoran y pretenden contribuir a su reformulación. Desde esta perspectiva, tales disciplinas no son partes de la ciencia

\footnotetext{
14 "Del conocimiento de las normas jurídicas elaboradas por las decisiones de los tribunales dependen la vida, la fortuna y la libertad de todos los hombres de la nación”. J. Bentham, Fragmento sobre el gobierno, pág. 24.

${ }^{15}$ La poca importancia dada por nuestra tradición jurídica al problema de los vacíos en la ley, se expresa en el hecho de que esta materia se encuentre regulada por la ley153 de 1887, cuyo artículo 13 establece: "La costumbre, siendo general y conforme con la moral cristiana, constituye derecho, a falta de legislación positiva”. La Corte Constitucional mediante la sentencia C-224 de 1994 declaró su exequibilidad o existencia jurídica; en una decisión judicial que intenta separar el derecho de la moral, pero fracasa debido a las incoherencias argumentativas y conceptuales.

${ }^{16}$ Para Bentham la Jurisprudencia se divide en dos partes: a. el arte de la legislación, también denominada jurisprudencia censorial, cuya tarea es indagar sobre qué deba ser el derecho; y b. la Jurisprudencia expositiva: aquella que se dedica a determinar lo que la ley es (jurisprudencia expositiva) Véase, J. Bentham, The Principles of morals and legislation, pág. 324. El desarrollo de esta concepción será elaborado también por el discípulo de Bentham J. Austin, quien formuló una distinción clásica entre Jurisprudencia y Ciencia de la Legislación, (entre el ser y deber ser del Derecho).
} 
jurídica, "sino partes respectivas de la filosofía, la sociología y la antropología generales" 17 . Se trata de una concepción que excluye del saber jurídico la tarea conceptual-valorativa, el conocimiento de la realidad social en que surgen y se aplican las normas y el tipo de sujeto al que están destinadas. Las consecuencias que para la disciplina ha traído esta forma de entender el objeto son bastante conocidas ${ }^{18}$. El término ciencia jurídica fue asimilado en nuestra tradición a dogmática jurídica; caracterizada como un saber científico y descriptivo. El saber se consideró desprovisto de valoraciones - sobre la justicia o eficacia de sus normas - y de elementos prácticos; como los problemas de decisión en los casos particulares. La dogmática exige al investigador neutralidad frente a las valoraciones, rigor en la descripción y unidad metodológica. La unidad se expresa en el acuerdo sobre dos reglas básicas.

La primera regla se refiere a la abdicación valorativa; mediante la cual se afirma la necesidad de que el jurista renuncie a dar opiniones sobre cómo deba ser el derecho. El jurista debe dedicarse a describir las normas que forman el ordenamiento jurídico, (ordenamiento jurídico positivo). Esta regla supone que el jurista acepta de manera acrítica la legislación ${ }^{19}$ y respeta la idea del legislador racional o sabio. Le impone la obligación de someterse incondicionalmente a la voluntad de quienes hacen la ley, entendida como ley positiva.

La segunda regla de la dogmática señala que el jurista debe abordar el ordenamiento jurídico como sistema. Este principio no considera al derecho como agregado incoherente de normas, sino como un sistema coherente, desprovisto de vacíos o lagunas. Se trata de la convicción sobre la racionalidad intrínseca del derecho, que autores como Hans Kelsen - en sus obras tempranas- defenderán como central en la ciencia jurídica. La norma pertenece al sistema porque se basa en una supuesta Constitución última ${ }^{20}$, o porque existe una regla de reconocimiento a partir de la cual los funcionarios, tribunales y particulares aceptan que aquello dicho por la Constitución es derecho ${ }^{21}$.

\footnotetext{
${ }^{17}$ E. Díaz, Sociología y filosofía del Derecho, Ed. Taurus, Madrid, 1980.

${ }^{18}$ Durante muchos años la enseñanza en algunas escuelas de derecho ha estado guiada por una convicción: se considera jurista solo a aquel profesional conocedor de las normas que conforman un ordenamiento jurídico particular. La actividad pretende ser científica, porque se trata de describir los contenidos normativos con supuesto rigory neutralidad; Este fenómeno ha dado lugar a que los abogados sean técnicos especialistas en el conocimiento de las normas, pero desprovistos de un conocimiento sólido sobre el contexto social, político, económico y moral en el cual aquellas surgen y se aplican.

${ }^{19}$ La pretensión de abdicación es considerada por algunos críticos como imposible, porque cualquier jurista está inmerso en una ideología determinada, de la que le resulta imposible desprenderse, en su tarea dogmática. A. Calsamiglia, "La ciencia jurídica", en Enciclopedia Iberoamericana de Filosofia, Editorial Trotta, Madrid, 1996, pág. 22.

${ }^{20}$ Para H. Kelsen el fundamento de validez del ordenamiento jurídico es una última Constitución, que no corresponde a las constituciones de los Estados particulares en tanto es un supuesto teórico o hipótesis. En virtud de dicho supuesto se asume la existencia histórica de una primera constitución o norma fundamental, según la cual fueron creadas las normas jurídicas. Tomado de H. Kelsen, Teoría pura del Derecho, Editorial Porrúa, México D.F., 1995, Págs 201 y 202.

${ }^{21}$ Para H.L. A. Hart el fundamento de validez de las normas del ordenamiento es la regla de reconocimiento, que reemplazaría esa supuesta constitución última de Kelsen y cuyo contenido reza: "lo que
} 
Entre los elementos que nuestra tradición desconoció de la formulación metodológica de Bentham, se encuentran el reconocimiento de las limitaciones del ordenamiento jurídico. Este podía reducirse a un sistema de normas incoherente e incompleto, por la ausencia de racionalidad en su elaboración ${ }^{22}$. Bentham sabía que la razón y el poder no siempre coinciden, situación que deja sin fundamento la ficción del legislador racional, propia del paradigma dominante de ciencia jurídica. De igual manera consideraba, tal como citamos líneas arriba, que un sistema jurídico no progresa sin la jurisprudencia censorial. La tarea valorativa del censor no sólo impedía el rezago del derecho frente a los cambios sociales, sino que formaba parte interna de la disciplina - Jurisprudencia -, al lado de la parte expositiva o descriptiva.

La dogmática como método de trabajo del jurista, bajo la forma que adoptó en nuestra tradición, se define como la parte científica del derecho, en la cual los juristas deben abstenerse de valorar las normas; haciendo abstracción de los problemas prácticos o de aplicación de las normas. Las críticas actuales al saber dogmático se refieren a la imposibilidad de separar la descripción del derecho de su valoración. Un estudio riguroso de las normas necesariamente llevará al investigador a develar los vacíos, incongruencias y demás problemas del sistema jurídico. Esto significa en la práctica la realización de una labor valorativa de dichas normas. Otro elemento descuidado por la tradición formalista es una tercera regla de la dogmática referida a la resolución justa y eficiente de los casos por parte de los jueces ${ }^{23}$. Se considera que a fin de obtener de la tarea interpretativa una consecuencia justa y bien recibida por los ciudadanos, se deben ponderar las consecuencias de la decisión. Esta regla busca garantizar el valor de la justicia material y la eficiencia como valores básicos de la sociedad y en esa medida, irrenunciables.

d. El papel tradicional del jurista.

En las consideraciones sobre el método va involucrada la tarea que la concepción tradicional deja al jurista, es decir la descripción de las normas del ordenamiento jurídico, y en el caso del juez, la aplicación deductiva de dichas normas a los casos particulares. El supuesto básico de tal asignación es el papel predominante del legislador, quien, al ejercer el poder político es el único facultado para crear las normas del ordenamiento. Nuestra tradición tomó la noción de soberano formulada por Bentham y su discípulo Austin. Para Austin, la voluntad del soberano sirve de criterio para diferenciar las normas jurídicas del resto de normas sociales ${ }^{24}$. Por soberano Austin no entiende al monarca, sino al legislador último, que en un sistema

\footnotetext{
la Constitución dice es derecho", norma última, por encima de la cual no habría otra que le otorgara a su vez validez jurídica y que existe como una práctica de los tribunales, funcionarios y particulares, quienes aunque no la formulen expresamente suponen su existencia como un hecho social. Tomado de H.L.A. Hart, El concepto de Derecho, Abeledo-Perrot, Buenos Aires, 1995, Págs 125 - 137.

${ }^{22}$ La incompletud del sistema obliga al jurista a acudir a algo externo al conjunto de normas, en su búsqueda de soluciones a los casos particulares, con lo que se desborda el método puramente descriptivo

${ }^{23}$ Sobre las características y límites de la dogmática jurídica, véase: A. Calsamiglia, Introducción a la Ciencia Jurídica, págs 101 - 109 .

24. Véase D. Lyons, Etica y Derecho, Ariel, Barcelona, 1989, págs 57 - 60.
} 
democrático coincide con el parlamento. La noción de soberano es central en la definición del derecho como conjunto de normas coactivas, creadas por él. Aunque para Bentham el carácter coactivo de las normas era un criterio diferenciador más preciso, el soberano ocupaba igualmente un lugar predominante.

El legislador en nuestra tradición jurídica tiene exclusividad sobre el trabajo creador de normas, pues solo él goza de la autoridad necesaria para mandar, prohibir, facultar o permitir algo a los ciudadanos ${ }^{25}$. El principio de legalidad, como parte básica de dicha tradición, garantiza que las disposiciones del legislador lo cobijen de igual manera, eliminando cualquier posibilidad de despotismo. Sin embargo, ese principio no impide que el juez sea considerado como su subordinado; posición que comparte con los abogados y los juristas teóricos. La concepción tradicional ve en el juez un siervo de la voluntad del legislador. Su tarea básica se reduce a ser "la boca por la que la ley habla", para lo cual debe utilizar los métodos de interpretación establecidos por la escuela de la exégesis ${ }^{26}$. Estos métodos garantizan la seguridad jurídica - ese es el supuesto -, mediante su incorporación a la legislación particular del Estado. Los abogados deben basar su tarea predictiva en un estudio riguroso de las normas jurídicas válidas, como forma de obtener aplicaciones de su contenido favorables a los intereses que ellos representan. El teórico del derecho, por su parte, debe encargase de la descripción normativa y dar precisión a los conceptos contenidos en el ordenamiento jurídico.

\section{e. Modificaciones a la concepción tradicional del derecho.}

La tradición jurídica dominante en Colombia hasta hace una década, corresponde, en términos generales, al esquema esbozado en este artículo. Sin embargo, durante estos años hemos asistido a una profundización de la influencia de la cultura anglosajona sobre el resto del mundo y en particular sobre los países latinoamericanos. De dicha cultura forma parte esencial la tradición jurídica del common law, para la cual los precedentes judiciales, entendidos como normas particulares que tienen el poder de suplir o contener la legislación, son considerados como elemento esencial del derecho. A ello se suman los poderes que tienen los jueces constitucionales de interpretar la Constitución; ellos en sus decisiones aislan de las contingencias políticas una parte significativa del derecho ${ }^{27}$. La incorporación de algunos elementos del sistema anglosajón a nuestro ordenamiento jurídico es consecuencia normal del

\footnotetext{
${ }^{25} \mathrm{He}$ descrito aquí el conjunto de acciones que contienen las normas jurídicas. Véase H. Kelsen, ob. Cit, págs $28-30$.

${ }^{26}$ Denominación dada a una Escuela de interpretación jurídica de inspiración francesa, cuyo origen se remonta al año de 1804 y cuyos principales rasgos son: el derecho se reduce a la ley, los tribunales deben establecer la existencia de los hechos, de los que se derivarán determinadas consecuencias jurídicas. La interpretación exegética supone que el derecho es un sistema completo, coherente, que contempla soluciones a todos los casos particulares y en el cual consta una única regla aplicable al mismo, desprovista de ambigüedad. El juez debe hacer una deducción silogística, en la cual la premisa mayor es la norma, la premisa menor la conducta y la consecuencia corresponde a la decisión. Véase, Ch. Perelman, La lógica jurídica y la nueva retórica, cit., págs $37-40$.

${ }^{27}$ C.S. Nino, Derecho, Moral y política, Ariel, Barcelona, 1994, págs 12, 13.
} 
proceso de globalización, interdependencia de los estados nacionales que opera en los ámbitos cultural, ideológico, económico, jurídico, etc. La erosión de la soberanía propia del Estado-Nación conlleva necesariamente la pérdida del poder del legislador para dictar, con exclusividad, las normas que guían la conducta ciudadana y sirven de soporte a la labor predictiva. Esta pérdida se da en beneficio de las reglas de juego internacionales. El nuevo status del derecho internacional resulta paradójico. Durante la vigencia de la concepción tradicional se discutían con escepticismo las posibilidades de reconocer como "derecho" a sus normas, por la ausencia del elemento coactivo. En la actualidad, hay una mayor conciencia sobre su carácter vinculante. La incorporación descrita de los elementos de una tradición jurídica en otra, ${ }^{28}$ se inició con el establecimiento de normas y prácticas propias del sistema acusatorio, a nuestro derecho penal y se ha ido consolidando mediante la interpretación constitucional realizada por la Corte durante la última década. El Magistrado Carlos Mejía Escobar, Presidente de la Sala penal de la Corte Suprema de Justicia, ha señalado con relación al sistema acusatorio: "El sistema colombiano contiene elementos de tendencia acusatoria, universalmente aceptados: la desconcentración de funciones básicas del procedimiento, la disminución de facultades oficiosas por parte de la judicatura, la pretensión de que el juicio sea oral y algunas instituciones propias del principio de oportunidad" ${ }^{29}$. Hay sin embargo, otros elementos que faltarían para clasificar a nuestro sistema como acusatorio. El propio doctor Mejía los enuncia: “(...) el sistema colombiano carece de otras como la intervención de jurados, la concentración de la prueba que se practica en el juicio como fundamento exclusivo de la sentencia, la concepción de la fase investigativa como etapa meramente preparatoria del juicio, y en general el desarrollo del procedimiento como proceso puro de partes".

Al cambio también ha contribuido la necesidad de los jueces de tutela de interpretar y aplicar un listado de derechos individuales, sociales, económicos y culturales, incluídos en la Constitución Política. La cuestión del sentido y alcance de derechos fundamentales, en el marco de un Estado social, requiere de herramientas conceptuales que se encuentran muy elaboradas en la literatura norteamericana e inglesa de los últimos siglos. Proferir fallos sobre aborto o eutanasia, para citar dos casos, requiere alguna reflexión sobre los conceptos de persona, calidad de vida, disponibilidad de vida, etc. Estas cuestiones se han debatido ampliamente en el marco de dicha tradición.

f. La integración de los precedentes a nuestra noción de derecho.

En Colombia presenciamos la incorporación de algunos elementos de la tradición anglosajona a las prácticas jurídicas actuales. Los precedentes judiciales entran a constituirse en fuente básica de derecho, - al lado de las normas jurídicas-. Este proceso

\footnotetext{
${ }^{28}$ A comienzos de la década de los 80 un filósofo del Derecho argentino, Genaro Carrió, explicaba cómo las tradiciones continental y del common law se desenvolvian en un ambiente de ignorancia mutua, lo que las llevó a encerrarse en sí mismas y a que los debates propios de cada tradición fueran tratados como un asunto de familia. Véase, G. Carrió, Dworkin y el positivismo jurídico, en Cuadernos de crítica 16, Instituto de Investigaciones filosóficas Universidad Nacional Autónoma de México, 1981, págs 7 y 8.

${ }^{29}$ Ambito jurídico, separata bimestral, academia foro justicia. Julio de 2001.
} 
es el resultado de la tarea hermeneútica realizada por el tribunal constitucional, durante la última década. El tribunal constitucional estableció, en un primer momento, la noción de "doctrina constitucional", para referirse al conjunto de decisiones que tomaba en la revisión de los fallos de tutela. Mediante esos fallos se fijaba el sentido y alcance de los derechos fundamentales. Estas decisiones, trascendían el efecto entre las partes y se tornan obligatorias para todos, es decir tienen el mismo efecto que la ley creada por el legislador (erga-omnes). A esta doctrina se le conoció como doctrina "Angarita", nombre tomado de su defensor, el magistrado Ciro Angarita; y fue derrotada con posterioridad, mediante la sentencia C-131 de 1993.

La Corte mediante el recurso a la noción de cosa juzgada, ha dado carácter obligatorio a algunas de sus decisiones; las cuales se consideran pautas que unifican y orientan la interpretación constitucional. Esto impone a los jueces el deber de utilizar esas decisiones como precedentes para los casos similares, a fin de respetar el principio de igualdad - situaciones similares deben decidirse de igual manera - o el principio de cosa juzgada, consagrado en el artículo 243 de la Constitución: "Los fallos que la Corte dicte en ejercicio del control jurisdiccional hacen tránsito a cosa juzgada constitucional". Las sentencias de unificación, e incluso las de constitucionalidad, al tener efectos de cosa juzgada pueden considerarse como precedentes, o decisiones que deberán ser acatados por los jueces en los casos futuros.

Esta incorporación de los precedentes como fuentes primarias de derecho no se ha dado sin tropiezos. La Corte debió reconocer el contenido del artículo 230 de la Constitución: "Los jueces en sus providencias sólo están sometidos al imperio de la ley (...)” y enfrentó diversos intentos del legislador por poner límites a su capacidad de generar derecho ${ }^{30}$. Tales intentos se expresaron en el decreto reglamentario de la acción de tutela, en el sentido de reducir los efectos de la decisión a las partes vinculadas; y también en la ley estatutaria de la administración de Justicia. La Corte utilizó con posterioridad su facultad de determinar la constitucionalidad de las leyes para eliminar tales restricciones a su poder, declarando inconstitucionales los artículos pertinentes de la ley estatutaria Así mismo, ha esgrimido frente al legislador su autonomía institucional, como la capacidad de fijar ella misma el efecto y alcance de sus fallos. Y ha manifestado que en atención al principio de cosa juzgada, sus fallos pueden tener carácter obligatorio.

Los juristas mediante el estudio de las sentencias pertinentes señalan la existencia de contradicciones en la posición de la Corte. Concluyen que en las decisiones se acepta el carácter "auxiliar" de sus propios fallos y la consiguiente supremacía de la ley, aunque en la práctica ha existido una lucha con el legislador, por controlar el sistema de fuentes del derecho. Las sentencias de unificación y el recurso a las nociones de autonomía institucional y de igualdad, serían parte de estas prácticas ${ }^{31}$.

Con relación a las decisiones judiciales, lo novedoso no es el status de normas que se les otorga; incluso Kelsen se refería a ellas como normas particulares. Es su

\footnotetext{
${ }^{30}$ Sobre la historia de esta disputa Corte-Congreso por la hegemonía sobre la creación de pautas generales y obligatorias, se encuentra un estudio interesante de D. López Medina, "El valor del precedente constitucional”, en Derecho constitucional perspectivas criticas, Facultad de Derecho de la Universidad de los Andes y siglo del Hombre editores, Bogotá, 1999. Págs 123 - 146.

${ }^{31}$ Estas conclusiones se encuentran en el texto de D. López Medina, ob.cit, págs 144- 146.
} 
incorporación a nuestro ordenamiento como precedentes, es decir como normas con efectos generales, que imponen un deber de obediencia a los juristas. Esta perspectiva hace de los precedentes una parte esencial del derecho, que debe ser considerada, para el éxito de la labor predictiva propia de la seguridad jurídica. Su lugar en el esquema de fuentes del derecho, deja de ser secundario y subsidiario - solo se consideran fuentes en casos de vacíos legales-, para tornarse en fuente primaria.

\section{g. La incorporación de los principios al concepto de Derecho.}

Tal como hemos señalado, algunas prácticas jurídicas propias del common law se incorporan de modo paulatino a nuestro sistema jurídico. De igual forma, y como resultado de lo anterior, discusiones teóricas que hace un par de años eran exclusivas de ingleses y norteamericanos, hoy son muy relevantes para la comprensión del tipo de derecho que impera entre nosotros. Uno de los principales teóricos de la tradición norteamericana es Ronald Dworkin, quien ha dedicado buena parte de su esfuerzo intelectual a develar las limitaciones del positivismo. Su crítica pone de manifiesto la forma como el derecho se amplía, más allá de las normas coactivas producidas por el poder político.

Dworkin considera que las normas no pueden dar cuenta de la totalidad del fenómeno jurídico. Reducir el derecho al sistema de normas es desconocer la existencia de los principios y las directrices políticas, cuya naturaleza es distinta a la de aquellas. Para el teórico norteamericano, los abogados y los jueces al decidir un proceso, apelan no solo a normas jurídicas simples (las cuales pueden ser identificadas mediante algún criterio como la coerción), sino además a principios jurídicos. Estos son diferentes a las normas; las cuales tienen una estructura dual, contienen un supuesto jurídico y una consecuencia jurídica.. Una vez satisfecha la condición plasmada como supuesto se seguirá la consecuencia de manera inmediata. Los principios en cambio tienen una estructura simple, en tanto se limitan a enunciar una razón ${ }^{32}$. En aquello casos en los cuales se presenten conflictos entre principios, el juez deberá decidirse por aquel que posea mayor peso. El principio que ceda en dicho caso seguirá formando parte del ordenamiento jurídico y podría, en otro caso, ser considerado como de mayor importancia o relevancia ${ }^{33}$. Las partes tienen el derecho ${ }^{34}$ de ver resuelta su situación conforme al derecho preexistente. Por esto la crítica dworkiniana busca demostrar la forma como operan tales principios en el derecho. Se trata de impedir la discrecionalidad judicial, es decir, que el juez decida de acuerdo a sus opiniones, creencias, o ideologías.

El objeto del derecho no puede agotarse en reglas reconocibles por su conformidad con un superior - Constitución supuesta o un hecho social -. En él hay principios aplicables a los casos fáciles y a los difíciles que no pueden ser identificados mediante

\footnotetext{
${ }^{32}$ La explicación de esta teoría se encuentra en el texto de R. Dworkin, Los derechos en serio, Ariel, Barcelona, 1995, pág 75.

${ }^{33}$ Un ejemplo de este modo de proceder lo podríamos encontrar en algunas sentencias de la Corte Constitucional colombiana, cuando decide casos en que debe ponderar el principio de libre desarrollo a la personalidad y algún otro principio como el respeto a la vida o la dignidad humana.

${ }^{34}$ Se trata del derecho subjetivo o facultad. Vgr, tengo derecho a esperar que sea aplicada la justicia.
} 
la regla de reconocimiento propuesta por H.L.A. Hart. El soporte del positivismo a partir del cual los "derechos y las obligaciones sólo se pueden derivar de reglas jurídicas, cuya validez se da en términos de la regla de reconocimiento", tampoco se sostiene, porque los principios también pueden crear derechos y obligaciones ${ }^{35}$.

En consideración a los anteriores límites positivistas, Dworkin plantea la necesidad de ampliar el concepto de derecho, a fin de incluir los principios que justifican las prácticas jurídicas. Esto permite a los jueces encontrar en los casos difíciles los principios que justifiquen de la mejor manera posible las reglas vigentes, sin necesidad de crear normas jurídicas. Para Dworkin la adjudicación o aplicación del derecho está gobernada por la integridad, entendida como el compromiso de las autoridades públicas de tratar a los particulares de manera consistente con los principios de moralidad política plasmados en las instituciones de la comunidad. Se trata de un vínculo intrínseco entre el derecho y la moral: aquel contiene en sí mismo los principios de moralidad política pactados contractualmente.

La inclusión de los principios en el contenido del saber, no es un elemento ausente de nuestra tradición jurídica; lo novedoso es el lugar que ocupan en el ordenamiento. Los principios eran considerados fuentes secundarias de derecho, aplicables solo en aquellos casos en que no existiesen normas expresas para regular el caso sujeto a examen. Su exclusión como fuentes de obligación era resultado del carácter formal que les daba el ordenamiento jurídico; es decir, el sentido de enunciados que pretenden guiar la conducta de juristas y gobernantes, sin un contenido material con validez normativa. Este carácter subsidiario cede su lugar a un papel más activo, en la medida en que los principios se tornan normativos, - son capaces de imponer derechos y obligaciones $-{ }^{36}$.

h. Conclusión sobre el Derecho y la seguridad jurídica en la actualidad.

\footnotetext{
${ }^{35}$ Las autoridades judiciales colombianas conceden tutelas para salvaguardar no solamente los derechos normas - de los asociados sino también los principios consagrados positivamente en la Carta Política. En las sentencias encargada de explicar el sentido y alcance de los principios constitucionales, la Corte ha señalado que no se trata de declaraciones éticas, sino de normas jurídicas de carácter vinculante para todas las autoridades. Ver, sentencia T-499 de agosto de 1992, sobre el principio de dignidad humana. Con relación al principio que consagra el Estado social de derecho, la Corte ha manifestado: "Los caracteres esenciales del Estado tienen que ver no sólo con la organización entre poderes y la producción y aplicación del derecho, sino también y de manera especial, con el compromiso por la defensa de contenidos jurídicos materiales (...) la Constitución está concebida de tal manera que la parte orgánica de la misma sólo adquiere sentido y razón de ser como aplicación y puesta en obra de los principios y de los derechos inscritos en la parte dogmática de la misma (...) No es posible, entonces, interpretar una institución o un procedimiento previsto por la Constitución por fuera de los contenidos materiales plasmados en los principios y derechos fundamentales", Sentencia T-406 de junio de 1992.

${ }^{36} \mathrm{La}$ concepción tradicional del derecho ha sido clara en excluir a los principios como fuentes de obligaciones. En este sentido afirma A. Valencia Zea: "La doctrina actual señala como hechos generadores de obligaciones a los contratos y las declaraciones unilaterales de voluntad, a los hechos ilícitos, y a los estados especiales o situaciones de derecho o de hecho que, unidos a determinadas circunstancias o supuestos, son susceptibles de engendrar una obligación" Tomado de A. Valencia Zea, Derecho civil de las obligaciones, Temis, Bogotá, 1990, págs 45 y 46.
} 
A pesar de los límites del enfoque normativo, es necesario reconocer que en nuestro país el derecho es aún, en buena parte, un conjunto de normas creadas por el poder político. El trabajo interpretativo de la Corte Constitucional ha introducido las nociones de precedente y de principios constitucionales como fuentes primarias de derecho. La metodología es descriptivo - valorativa, incluso en la dogmática jurídica, como aquella parte científica del saber que pretende dar elementos a los juristas y jueces para la interpretación y la decisión judicial. ${ }^{37}$. Como la valoración moral y política de las normas y principios es parte ineludible de su aplicación, se reconoce que los juristas no pueden ser totalmente neutrales.

Las transformaciones del saber señaladas requieren de un cierto acuerdo por parte de la comunidad jurídica, en torno a una definición válida para nuestra nueva realidad. El acuerdo permitirá la restauración de un tipo distinto de seguridad jurídica. Proponemos entonces una definición, para ser tenida en cuenta por los miembros de esa comunidad. El Derecho puede ser definido como un saber cuyo objeto es un conjunto de normas, principios positivos y precedentes, establecidos para regular las relaciones intersubjetivas de los miembros de la comunidad política. El fin que persigue es compatibilizar los distintos intereses presentes en dicha comunidad, como condición para la convivencia pacífica. Su objeto es pensado de modo activo, en sus procesos de creación, aplicación e interpretación. Su método es descriptivo y valorativo, en tanto involucra la valoración moral y política del objeto.

La anterior definición supone el abandono de la vieja escisión entre disciplinas fundamentales y auxiliares. En su lugar reconoce el papel que desempeñan, para el estudio del Derecho, las teorías de la justicia, de la legitimidad política, de la adjudicación o competencia judicial y de la obediencia al Derecho ${ }^{38}$. Deja de lado otras formas jurídicas básicas como la costumbre, que a pesar de su carácter de fuente primaria en ámbitos como el comercial, no logran más que ser reconocidas como fuentes supletivas de derecho - suplen los vacíos de la legislación -.

Quienes esperen encontrar en la ley positiva respuestas a la forma como se decidirán los conflictos que afectan la economía, y los demás ámbitos de interés nacional, estarán buscando un tipo de seguridad jurídica que no es posible en el contexto colombiano actual. Un jurista vinculado a una organización cualquiera debe conocer a fondo los principios del derecho colombiano, así como los precedentes relacionados con materias puntuales que afecten la economía en general y la actividad económica particular que su organización desarrolla. Ese estudio debe servirle para prever lo que hará la Corte en aquellos asuntos en los cuales se presenten conflictos de intereses, que vinculen la actividad productiva particular.

Desde esta nueva perspectiva, los precedentes determinan cuáles normas del ordenamiento jurídico podemos razonablemente esperar que sean aplicadas por los jueces hacia el futuro. El éxito predictivo depende a su vez de la capacidad del jurista

\footnotetext{
${ }^{37}$ Este punto es vital pues se deja de considerar a la descripción de las normas de un ordenamiento particular como la tarea propia del jurista, lo que obliga a las escuelas de Derecho a abordar el estudio de los fenómenos económico, político y moral en tanto centrales al concepto de Derecho y no como cuerpos extraños a lo propiamente jurídico.

${ }^{38}$ Véase A. Calsamiglia, "La ciencia jurídica”, págs 24 y 25.
} 
de interpretar las tendencias de los fallos en materia económica, y de caracterizar el tipo de Corte ante la cual la organización se enfrentará durante los nueve años que dure su periodo. Debe buscar estos datos mediante el estudio directo de los fallos, como trabajo cada vez más ineludible. Los resultados pueden optimizarse con una discusión interdisciplinaria sobre el contenido y alcance de las decisiones; que cobije al menos a economistas, juristas de tendencias ideológicas diversas u opuestas y empresarios. Deben buscarse además, en los resultados de las investigaciones jurídicas que realizan los observatorios de Justicia Constitucional y los centros de investigación jurídica del país.

\section{Bibliografía:}

J. Bentham, Fragmento sobre el gobierno, Aguilar, Madrid, 1973.

,The principles of morals and legislation, Prometheus Books, New York, 1988.

N. Bobbio, Teoría general del Derecho, Temis, Bogotá, 1997.

A. Calsamiglia, Introducción a la Ciencia jurídica, Ariel, Barcelona, 1990.

"La ciencia jurídica" R. Dworkin, Los derechos en serio, Ariel, Barcelona, 1995.

G. Carrió, Dworkin y el positivismo jurídico, en Cuadernos de crítica 16, Instituto de Investigaciones filosóficas Universidad Nacional Autónoma de México, 1981.

D. Held, La democracia y el orden global - del Estado moderno al gobierno cosmopolita, Paidós, Barcelona, 1997.

J. Jaramillo Uribe, El pensamiento colombiano en el siglo XIX, Temis, Bogotá, 1982.

H.L.A. Hart, El concepto de Derecho, Abeledo-Perrot, Buenos Aires, 1995.

R. Dworkin, Estudio preliminar de C. Rodríguez, La decisión judicial, Facultad de Derecho Universidad de los Andes, Siglo del Hombre Editores, Santafé de Bogotá, 1997. 2001.

S. Kalmanovitz, Las Instituciones colombianas en el siglo XX, Alfaomega, Bogotá,

H. Kelsen, Teoria pura del Derecho, Porrúa, México D.F., 1995.

D. Lyons, Etica y Derecho, Ariel, 1989.

C.S. Nino, Introducción al análisis del Derecho, Ariel, Barcelona, 1997. ,Derecho, Moral y Politica, Ariel, Barcelona, 1994.

R. E. Peña Peña, Constitución Politica de Colombia, Ecoe, Santafé de Bogotá, 1996.

Ch. Perelman, La lógica jurídica y la nueva retórica, Civitas, Madrid, 1988.

M. Reyes Mate, Enciclopedia Iberoamericana de Filosofía 11, Trotta, 1996.

Valencia Zea, Derecho Civil Tomo III de las obligaciones, Temis, Bogotá 1979.

Vázquez Carrizosa, El poder presidencial en Colombia, Enrique Dobry editor, Bogotá,

Varios autores, La Corte Constitucional el año de la consolidación, Facultad de derecho Uniandes y siglo del Hombre editores, Bogotá, 1998.

Derecho constitucional perspectivas criticas, Facultad de derecho Uniandes y siglo del Hombre editores, Bogotá, 1999.

, Revista Pensamiento Jurídico N. 12, "Justicia Comunitaria" Facultad de derecho, ciencias políticas y sociales de la Universidad Nacional de Colombia, Santafé de Bogotá, 2000. 